\title{
Applications of Circular Dichroism for Structural Analysis of Gelatin and Antimicrobial Peptides
}

\author{
Ramamourthy Gopal ${ }^{1}$, Jin Soon Park ${ }^{2}$, Chang Ho Seo ${ }^{3}$ and Yoonkyung Park ${ }^{2, *}$ \\ 1 Research Center for Proteineous Materials, Chosun University, Gwangju 501-759, Korea; \\ E-Mail: ramagopa@gmail.com \\ 2 Department of Biotechnology, Chosun University, Gwangju 501-759, Korea; \\ E-Mail: jsmw2001@naver.com \\ 3 Department of Bioinformatics, Kongju National University, Kongju, South Korea; E-Mail: \\ chseo@kongju.ac.kr \\ * Author to whom correspondence should be addressed; E-Mail: y_k_park@chosun.ac.kr; \\ Tel.: +82-62-230-6854; Fax: +82-62-225-6758.
}

Received: 31 January 2012; in revised form: 2 March 2012 / Accepted: 5 March 2012 /

Published: 8 March 2012

\begin{abstract}
Circular dichroism (CD) is a useful technique for monitoring changes in the conformation of antimicrobial peptides or gelatin. In this study, interactions between cationic peptides and gelatin were observed without affecting the triple helical content of the gelatin, which was more strongly affected by anionic surfactant. The peptides did not adopt a secondary structure in the presence of aqueous solution or Tween 80 , but a peptide secondary structure formed upon the addition of sodium dodecyl sulfate (SDS). The peptides bound to the phosphate group of lipopolysaccharide (LPS) and displayed an alpha-helical conformation while $(\mathrm{KW})_{4}$ adopted a folded conformation. Further, the peptides did not specifically interact with the fungal cell wall components of mannan or laminarin. Tryptophan blue shift assay indicated that these peptides interacted with SDS, LPS, and gelatin but not with Tween 80 , mannan, or laminarin. The peptides also displayed antibacterial activity against $P$. aeruginosa without cytotoxicity against $\mathrm{HaCaT}$ cells at MIC, except for HPA3NT3-analog peptide. In this study, we used a CD spectroscopic method to demonstrate the feasibility of peptide characterization in numerous environments. The CD method can thus be used as a screening method of gelatin-peptide interactions for use in wound healing applications.
\end{abstract}


Keywords: circular dichroism; antimicrobial peptides; reduced glutathione; gelatin; sodium dodecyl sulfate; Tween 80; cell wall components; lipopolysaccharide

\section{Introduction}

Circular dichroism (CD) spectroscopy is the most widespread technique used for estimating the secondary structures of proteins and polypeptides in solution [1]. This technique can be used to distinguish between unordered (random coil) and ordered (alpha-helix or beta-sheet) structures [2,3]. $\mathrm{CD}$ detects wavelength-dependent differences in the absorption of right and left circularly polarized light by optically active molecules such as peptides and proteins. The CD spectrum of unordered peptides is usually characterized by a single band below $200 \mathrm{~nm}$, whereas alpha-helical structures usually present two negative bands at 208 and $222 \mathrm{~nm}$ along with one positive band at $192 \mathrm{~nm}$; beta-sheet structures typically show a negative band at $217 \mathrm{~nm}$ and a positive band at $195 \mathrm{~nm}$. Most linear cationic antimicrobial peptides (AMPs) are in an unordered state in aqueous solution. As these molecules are amphipathic, they can adopt folded conformations in both hydrophobic and hydrophilic environments [4]. AMPs are generally variable in length, sequence, and structure (helical, beta-sheet, extended, and looped) [4-6]. Alpha-helical AMPs are one of the most abundant types of AMPs. CD methods are very useful for studying protein-ligand interactions and protein denaturation due to their quantitative nature. Thus, any change in the CD spectrum of a protein upon addition of ligand, denaturant, or heat is directly proportional to the amount of protein perturbed [7].

In this study, we synthesized $(\mathrm{KW})_{4}$ peptide based on previous data showing that $(\mathrm{KW})_{3}$ has antimicrobial activity [8]. Another peptide with antimicrobial activity, HPA3NT3-analog, was also used [9]. Furthermore, we used three natural peptides, NRC-16, magainin-II, and reduced glutathione (GSH), in this study. NRC-16 peptide is derived from flatfish genes [10] and shows potent antimicrobial activity. Magainin-II was originally isolated from the skin of African clawed frog, Xenopus laevis [11]. GSH is a water-soluble tripeptide composed of the amino acids cysteine, glutamic acid, and glycine. The biological (antimicrobial or antioxidative) activities of these peptides promote interactions with gelatin, an important connective tissue protein. Here, we used CD spectroscopy to monitor the gelatin response to these peptides, sodium dodecyl sulfate (SDS), or calcium chloride $\left(\mathrm{CaCl}_{2}\right)$. The structures and organization of the peptides in aqueous solution, SDS, Tween 80, lipopolysaccharide (LPS), mannan, or laminarin were determined using CD spectroscopy. The peptide-dependent interactions in gelatin, SDS, LPS, mannan, and laminarin were investigated by tryptophan (Trp) blue shift assay. Finally, the antibacterial and cytotoxicity activities of the peptides were determined.

\section{Results and Discussion}

Gelatin is a protein produced by acid and alkaline processing of collagen and is characterized by a three-chain structure in which individual helical chains are stranded in a superhelix about a common molecular axis [12-14]. The triple helical structure of gelatin can be quantified by using CD measurements [15]. In the present study, the CD spectra of gelatin showed two peaks, a negative peak at $205 \mathrm{~nm}$ suggesting a random coil conformation, and a positive peak at $222 \mathrm{~nm}$ characteristic of the 
triple-helial conformation of gelatin [16-19]. This positive peak corresponds to the typical maximum peak of collagen at $222 \mathrm{~nm}$ [20-27]. The triple helical structure of collagen was established by Ramachandran and Kartha [28], Rich and Crick [29], and Cowan et al. [30].

\subsection{Effects of Antimicrobial Peptides on Gelatin Conformation}

CD spectroscopy has been used to characterize the interactions between small molecules and collagen with the aim of determining collagen stability [24,25,27,31-33]. We have also characterized the effects of peptides on the structural conformation of gelatin for biomedical applications. We prefer gelatin over collagen since the cost of producing collagen-containing sheets is higher than that of gelatin-containing sheets. Additionally, gelatin is water-soluble compared to the acid and salt solubilility of collagen, which is very important in peptide-based drug development. The CD spectra of gelatin solutions treated with various concentrations of peptides at $25^{\circ} \mathrm{C}$ are shown in Figure 1.

Figure 1. Effects of peptides on Circular dichroism (CD) spectra of gelatin in the wavelength region from 250-190 $\mathrm{nm}$. Gelatin solution was treated with peptides at an increasing molar ratio of gelatin to peptide from 11:1 to 11:3 and incubated for $10 \mathrm{~min}$ at $25^{\circ} \mathrm{C}$. (A) (KW) $)_{4}$; (B) HPA3NT3-analog; (C) NRC-16; (D) Magainin-II; and (E) Reduced glutathione (GSH). CD spectra of $0.1 \%$ gelatin in the absence of peptides (solid line). Peptide concentrations were as follows: $50 \mu \mathrm{M}$ (dotted line), $100 \mu \mathrm{M}$ (dashed line), and 200 $\mu \mathrm{M}$ (dashed-dotted line). (F) CD spectra of gelatin in the absence (solid line) or presence of $1 \mathrm{mM}$ SDS (dotted line), $5 \mathrm{mM}$ SDS (dashed line), and $10 \mathrm{mM}$ SDS (dashed dotted line).
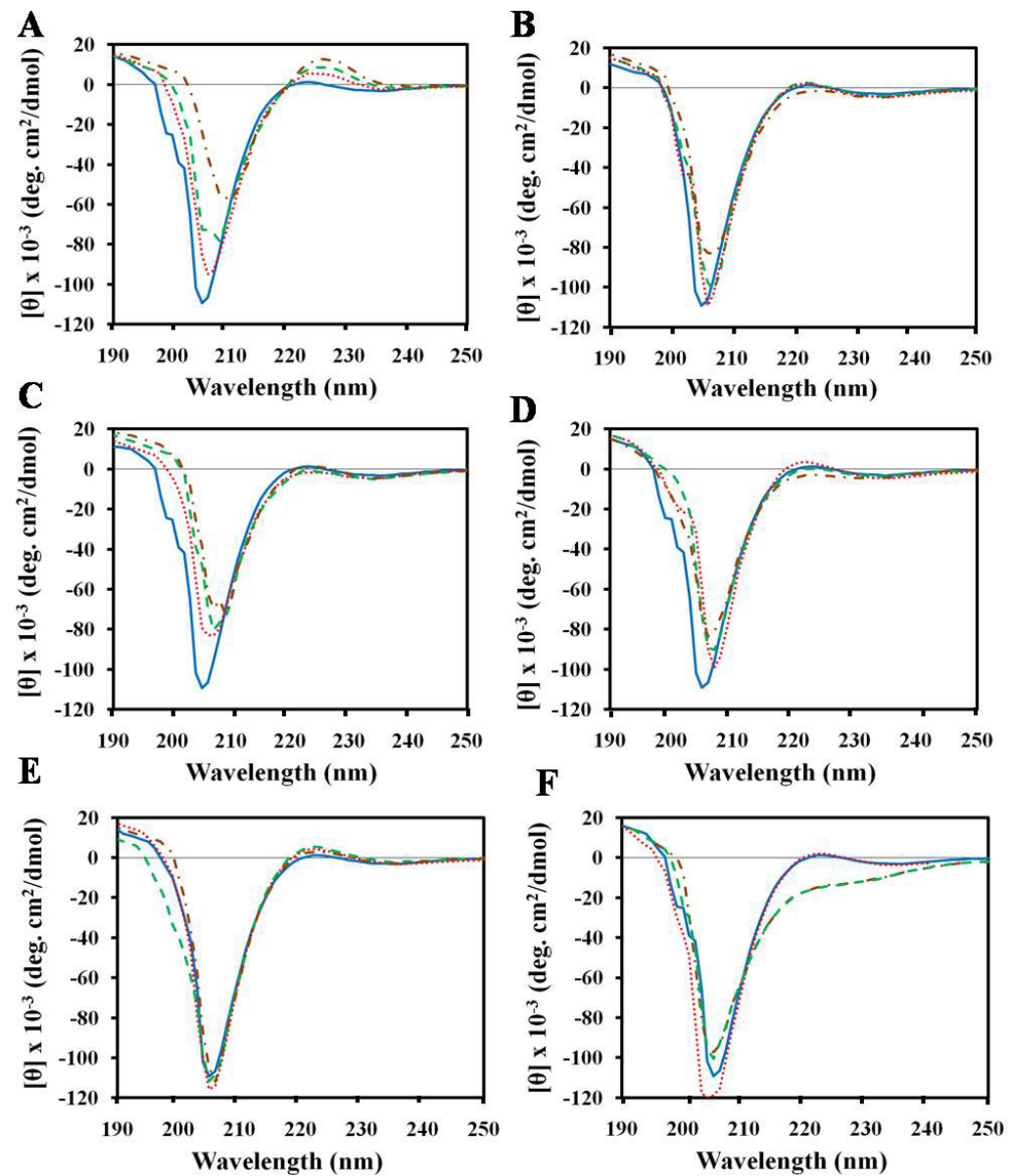
Compared to gelatin solution alone, the gelatin-peptide mixture displayed a marked decrease in the negative intensity of the dichroic spectrum as well as a slight decrease or increase in the molar ellipticity of the $222 \mathrm{~nm}$ bands. In addition, the negative peak shifted to a higher wavelength with increasing concentration of peptides. It has been reported that upon complete denaturation of gelatin, the positive peak at $222 \mathrm{~nm}$ disappears completely while the negative band shifts to nearly $230 \mathrm{~nm}$ [18]. However, our results showed that the addition of peptides to the gelatin solution did not cause the positive band at $222 \mathrm{~nm}$ to disappear, and there was a slight change in the negative band for the gelatin-peptide complex. This shows that peptide brought about a very slight change in the packing of the helices and did not change the triple helical conformation of gelatin. It was reported earlier that the interaction of collagen with glycoprotein [34] or small molecules such as polyphenols [24], curcumin [25], dicarboxylic acids [27], chromium [21], tannins [35], aldehydes [36], and 3,4-dihydroxyphenylalanine [37] does not alter the secondary structural conformation of collagen. Other studies reported that the triple helicity of collagen is not affected by AMP (pexiganan, an analog of magainin [38]) incorporation as confirmed by FT-IR [39]. Maintaining the triple helical conformation of gelatin or collagen-based biomaterials during preparation is important in eliciting the desired biomedical functions of both.

The CD spectra of gelatin with peptides displayed a decrease in negative ellipticity, suggesting that the peptides bound intra-molecularly, i.e., within a gelatin molecule, or promoted aggregation of gelatin. This point is likely correlated with aggregation of collagen-glycoprotein [34] or small molecule interactions [24,27]. On the other hand, the result that GSH did not increase negative ellipticity indicates that the gelatin molecules did not aggregate in the presence of GSH peptide. Thus, peptide promoted the native state of gelatin without affecting the peaks at $222 \mathrm{~nm}$, as confirmed by CD measurements. It has been suggested that the presence of GSH in the gelatin matrix may have antioxidant effects in a wound environment such as, preventing damage to important cellular components caused by reactive oxygen species such as free radicals and peroxides [40]. Moreover, the antioxidant function of biotinylated matrikine peptide has been shown to enhance wound healing in rats [41].

\subsection{Effect of SDS on Gelatin Conformation}

SDS is an anionic additive frequently used in studies on protein denaturation, and it is a well-known destabilizing agent of biopolymers. To confirm that the peptide does not alter the triple helical content of gelatin, we used SDS to denature gelatin. This procedure can be used to differentiate proteins with a triple helical conformation from others with a non-triple helical conformation [18]. Figure $1 \mathrm{~F}$ shows the $\mathrm{CD}$ spectra of a $0.1 \%$ gelatin solution in various concentrations of SDS at $25^{\circ} \mathrm{C}$. The triple helical content was reduced with increasing concentration of SDS. At increasing surfactant concentrations, absence of the $222 \mathrm{~nm}$ peak was observed. A previous study also reported that SDS eliminates the $222 \mathrm{~nm}$ peak [18]. Denaturation also occurred in $3 \mathrm{M} \mathrm{CaCl}_{2}$ solution, as indicated by the disappearance of the $222 \mathrm{~nm}$ peak (data not shown).

\subsection{Structures of Peptides in Aqueous and SDS Solution}

In order to examine the behavior of the AMPs in membrane-mimicking media, the CD spectra of the peptides were recorded in the absence and presence of $30 \mathrm{mM}$ SDS (Figure 2). The peptides showed a random coil conformation in aqueous solution. The conformations of the three peptides magainin-II, 
HPA3NT3-analog, and NRC-16 in SDS micelles included significant alpha-helical content. The alpha-helical contents of HPA3NT3-analog, magainin-II, and NRC-16 were 19, 29, and 59\%, respectively. In the presence of SDS micelles, $(\mathrm{KW})_{4}$ peptide exhibited a slightly folded conformation in which Trp residues were positioned mostly near the membrane-water interfacial region [42], suggesting interfacial association. Such a structural feature is believed to be important for the antibacterial activity of linear AMPs [43-46].

Figure 2. CD spectra of peptides in aqueous solution (dashed line) as well as in the presence of $0.1 \%$ Tween 80 (dotted line) and $30 \mathrm{mM}$ sodium dodecyl sulfate (SDS) (solid line). (A) (KW) 4 ; (B) HPA3NT3-analog; (C) NRC-16; and (D) Magainin-II.
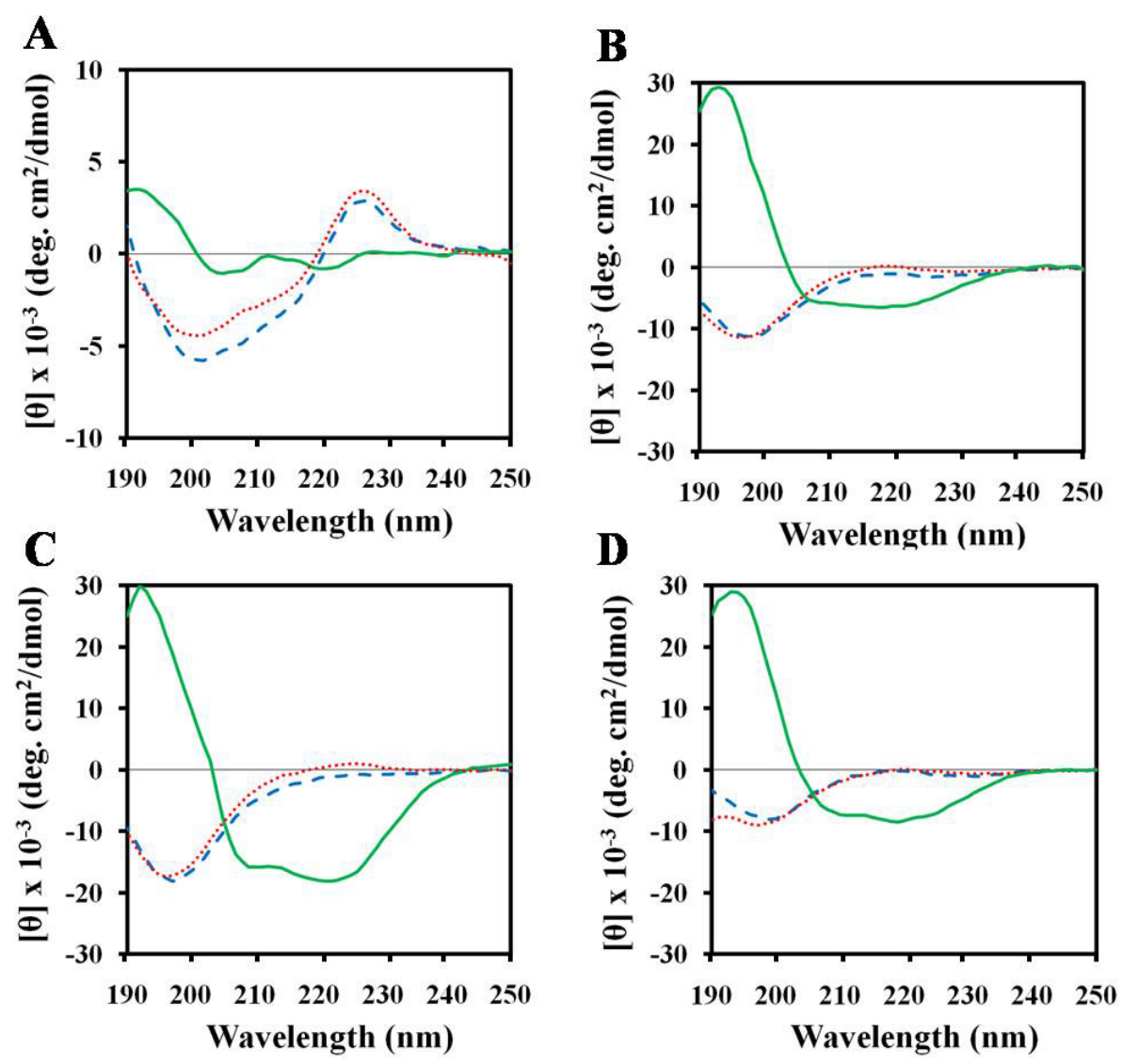

\subsection{Structures of Peptides in Nonionic Surfactant}

Tween 80 belongs to a class of nonionic surfactants that are frequently used in membrane protein solubilization, since they generally do not induce protein folding. Its chemical stability and high biocompatibility mean that it can be regarded as a strong candidate for future use in cosmetics and drug delivery. Based on CD, we investigated whether or not Tween 80 causes changes in peptide conformation. To accomplish this, we determined the conformations of peptides in the presence of Tween 80 (Figure 2). According to the results, Tween 80 did not alter peptide conformation. In addition, Trp containing $(\mathrm{KW})_{4}$ peptide showed a negative band at $200 \mathrm{~nm}$. This band is characteristic of a random coil, whereas the band at $225 \mathrm{~nm}$ was related to the Trp side chain in $(\mathrm{KW})_{4}$, which contributes to the CD signal in this spectral region [47-49]. On the other hand, the Trp side chain peak did not disappear in response to Tween 80 , indicating that there was no hydrophobic interaction between the peptide and 
Tween 80 . This is further supported by a previous study that did not find any general structural changes in insulin in the presence of Tween 80 , which suggests that only limited interactions, if any, occur between the two species in solution [50]. Clearly, this result shows that Tween 80 had no harmful effects on the peptides, which could be useful for the cosmetic application of these peptides using Tween 80 as a co-surfactant.

\subsection{Structures of Peptides in Cell Wall Components}

Finally, we used CD to investigate the conformational changes brought on by the interactions between peptides and cell wall components (LPS, mannan, and laminarin). CD spectroscopy showed that (KW) $)_{4}$ peptide displayed major conformational changes in association with LPS (Figure 3), which is a cell wall component of Gram-negative bacteria [51].

Figure 3. CD spectra of peptides in the presence of $0.1 \%$ mannan (dashed line), $0.1 \%$ laminarin (dotted line), and $0.1 \%$ lipopolysaccharide (LPS) (solid line). (A) (KW) 4 (B) HPA3NT3-analog; (C) NRC-16; and (D) Magainin-II.

$\mathbf{A}$
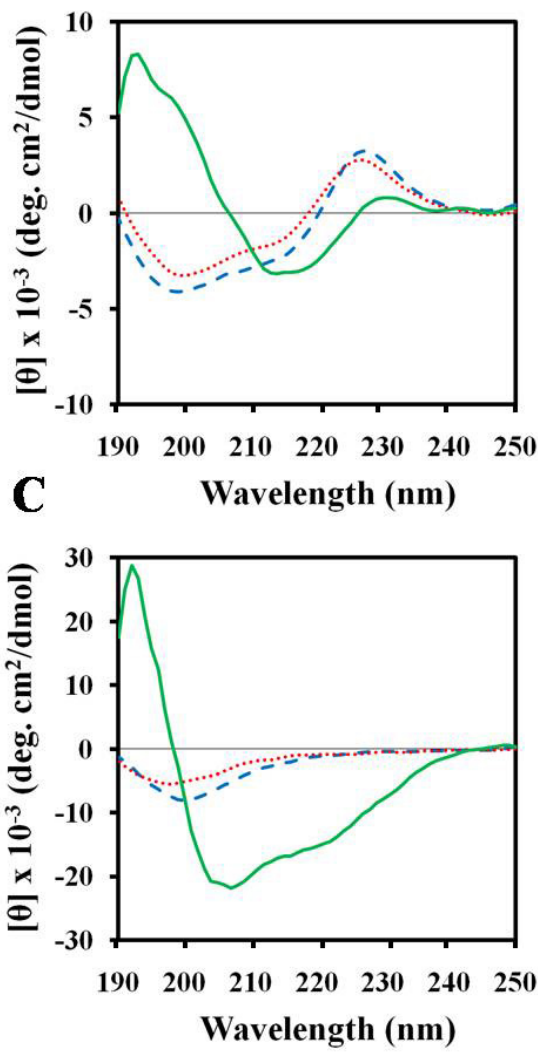

B

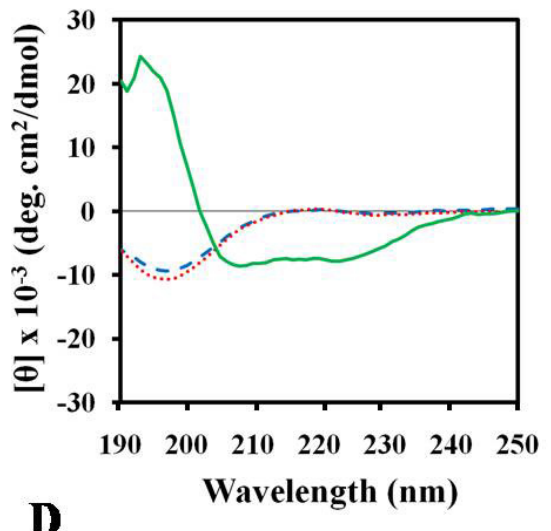

D

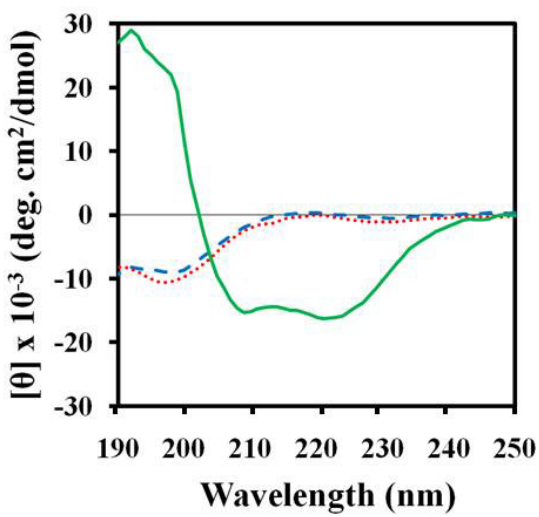

On the other hand, the peptides magainin-II, NRC-16, and HPA3NT3-analog transitioned from a random coil conformation to an alpha-helix upon interaction with LPS. Examples of other native, synthetic peptides that undergo alpha-helix formation upon LPS binding include melittin and magainin [52,53]. The ability of AMPs to bind LPS is a prerequisite for their antibacterial and endotoxin detoxifying activities [53]. Additionally, we determined whether or not binding of these peptides to fungal surfaces occurs via interaction with mannan or laminarin, which are major components of fungal cell walls. CD 
spectroscopy showed that these peptides displayed no major conformational changes associated with the fungal cell wall components mannan and laminarin (Figure 3). Therefore, it is clear that cell wall components did not affect the fungicidal activities of these peptides. This point suggests that the antifungal activity of AMPs is not affected by the removal of cell wall components $[54,55]$.

\subsection{Characterization of the Trp Environment Using Fluorescence Spectroscopy}

The peptide-binding process can also be followed by analysis of the Trp flourescence spectra (Table 1).

Table 1. Tryptophan (Trp) emission maxima of $2 \mu \mathrm{M}$ peptides in $10 \mathrm{mM}$ sodium phosphate buffer ( $\mathrm{pH} 7.2$ ), gelatin, sodium dodecyl sulfate (SDS), Tween 80, mannan, laminarin, and lipopolysaccharide (LPS).

\begin{tabular}{lccccccc}
\hline \multicolumn{7}{c}{ Blue shift $(\mathbf{n m})$} \\
\hline Peptides & $\lambda_{\max }$ buffer $(\mathbf{n m})$ & Gelatin & SDS & Tween & Mannan & Laminarin & LPS \\
\hline$(\mathrm{KW})_{4}$ & 355 & 8 & 10 & 0 & 0 & 0 & 10 \\
$\mathrm{NRC}-16$ & 356 & 8 & 25 & 0 & 0 & 0 & 17 \\
\hline
\end{tabular}

The $(\mathrm{KW})_{4}$ and NRC-16 peptides were used as they contain Trp residues in their sequences. In the presence of sodium phosphate (SP) buffer $(\mathrm{pH} 7.2),(\mathrm{KW})_{4}$ and NRC-16 peptides displayed fluorescence emission maxima at 355 and $356 \mathrm{~nm}$, respectively, which corroborates a previous report that the Trp residues of these peptides are located in a hydrophilic environment [56]. When these two peptides bound to gelatin, SDS micelles, and LPS, their fluorescence maxima shifted to shorter wavelengths, suggesting that the Trp side chains partitioned preferentially into more rigid, hydrophobic environments in gelatin, SDS, and LPS. This tendency is consistent with the CD spectra of these peptides in the presence of SDS micelles or LPS, which indicated a much more structured conformation upon binding (Figures 2,3). The recorded blue shift suggests that Trp residues were involved in the interaction with the cationic or hydrophobic domain of gelatin. Cationic peptides are thought to undergo electrostatic, cation- $\pi$, and hydrophobic interactions with gelatin or collagen. Gelatin consists of positively and negatively charged as well as hydrophobic domains. A previous study reported that hydrophobic interactions are mainly involved in the interactions between polyphenols and collagen [24]. Bioinformatics studies have also shown that quinone components interact with collagen through hydrophobic interactions [57]. Lysine (Lys) and arginine (Arg) residues mediate electrostatic interactions that attach cationic peptides to negatively charged amino acids in gelatin molecules. It has been suggested that cation- $\pi$ interactions between a protonated amine (Lys) or guanidine (Arg) side chain and an aromatic ring side-chain (phenylalanine, tyrosine, or Trp) promote peptide-gelatin interactions [58,59]. Therefore, electrostatic, hydrophobic, and cation- $\pi$ interactions might contribute to peptide-gelatin interactions.

\subsection{Antibacterial and Cytotoxicity Activities of Peptides}

A high level of microorganisms inhibits the normal wound healing process [60]. Wound infections are most frequently attributed to $P$. aeruginosa [61]. The MIC values of the peptides against $P$. aeruginosa under low salt (without $\mathrm{NaCl}$ ) and high salt (with $135 \mathrm{mM} \mathrm{NaCl}$ ) conditions are summarized in Table 2. 
Table 2. MICs of the peptides against drug-resistant $P$. aeruginosa.

\begin{tabular}{lcccc}
\hline & \multicolumn{5}{c}{ MIC $(\boldsymbol{\mu M})$} \\
\hline Resistant strains & $(\mathbf{K W})_{4}$ & HPA3NT3-analog & NRC-16 & Magainin-II \\
\hline P. aeruginosa 3547 & $16(32)$ & $8(16)$ & $4(8)$ & $32(64)$ \\
P. aeruginosa 3592 & $32(64)$ & $8(16)$ & $8(16)$ & $32(64)$ \\
P. aeruginosa 4007 & $16(32)$ & $4(16)$ & $4(8)$ & $32(32)$ \\
P. aeruginosa 4891 & $8(16)$ & $4(8)$ & $4(8)$ & $16(32)$ \\
\hline
\end{tabular}

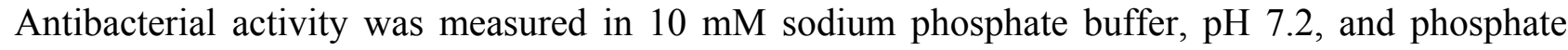
buffered saline, $\mathrm{pH} 7.2$ (number in the parentheses). NRC-16 peptide showed higher antibacterial activity than the other peptides. However, all of the peptides showed antibacterial activity against $P$. aeruginosa under both low and high salt conditions. The cytotoxic activities of the four peptides were assessed in $\mathrm{HaCaT}$ cells as a measurement of their toxicity towards higher order eukaryotic skin cells (Figure 4). At a concentration of $100 \mu \mathrm{M},(\mathrm{KW})_{4}$ and magainin-II peptides displayed non-cytotoxicity towards HaCaT cells, whereas NRC-16 and HPA3NT3-analog peptides showed cytotoxicity. Therefore, the $(\mathrm{KW})_{4}$ and magainin-II peptides were selective against bacteria with no effect on HaCaT cells. The ability to localize AMPs to wound sites is important for the effective treatment of bacterial infection at wound sites. Previous studies provide rationale for the application of collagen membranes to AMP delivery in infected wounds $[39,41,62]$. Other studies have reported that gelatin sheets containing bioactive molecules possess effective wound healing activity [63-66]. Gelatin gel shows non-cytotoxicty towards HaCaT cells [67] and is biodegradable in nature [68]. Additionally, it has good film forming properties and can be used in wound healing by preventing fluid loss due to exudation [69]. Gelatin gel is also effective in peptide delivery and has antibacterial effects at wound sites. Cationic peptides may also possess anticancer activity [70,71] or promote wound healing [72], and several AMPs are currently undergoing clinical trials [73]. Therefore, gelatin-peptides sheets could be useful for the inhibition of microbes at wound sites due to their wound healing properties.

Figure 4. Activities of the peptides against $\mathrm{HaCaT}$ cells. HaCaT cells $\left(2 \times 10^{4} /\right.$ well $)$ were incubated for $24 \mathrm{~h}$ with the indicated concentrations of $(\mathrm{KW})_{4}(+)$, HPA3NT3-analog $(\diamond)$, NRC-16 ( $\square)$, and magainin-II (o).

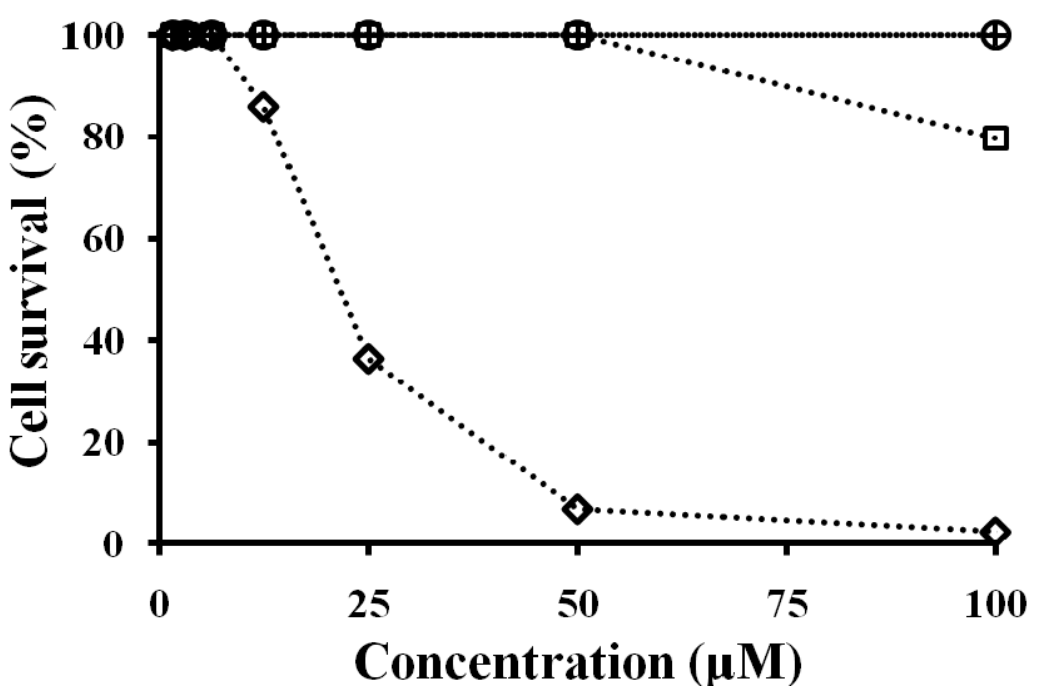




\section{Experimental Section}

\subsection{Materials}

Rink amide 4-methylbenzhydrylamine resin, fluoren-9-ylmethoxycarbonyl (Fmoc) amino acids, and other reagents for peptide synthesis were purchased from Calibochem-Novabiochem (La Jolla, CA, USA). LPS from $P$. aeruginosa, GSH, and Tween-80 were purchased from Sigma Chemical Co. (St. Louis, MO, USA). Granulated gelatin was obtained from DIFCO Laboratories (Detroit, MI, USA). The anionic surfactant, SDS, and $\mathrm{CaCl}_{2}$ were acquired from Calbiochem (La Jolla, CA, USA). All other reagents were of analytical grade. Buffers were prepared using double distilled water (Millipore Co.).

\subsection{Peptide Synthesis and Purification}

The peptides KWKWKWKW-NH $\mathrm{KH}_{2} \quad(\mathrm{KW})_{4}$, FKKLKKLFKKILKLK-NH 2 (HPA3NT3-analog), GWKKWLRKGAKHLGQAAIK-NH ${ }_{2}$ (NRC-16), and NMIEGVFAKGFKKASHLFKGIG (magainin-II) were synthesized by the solid-phase method using Fmoc chemistry on a solid support of Rink amide 4-methylbenzhydrydrylamine resin. Then, $0.1 \mathrm{M} \mathrm{N}$-hydroxy benzotriazole (HOBt) and $0.45 \mathrm{M} \mathrm{2-(1H-}$ benzotriazole-1-yil)-1,1,3,3-tetramethyluroniumhexafluorophosphate (HBTU) in dimethylformamide

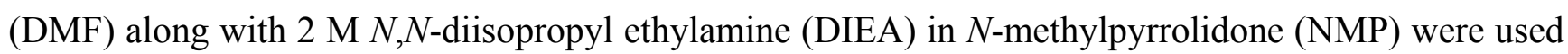
as a coupling reagent, and 10-fold excess Fmoc-amino acid was added during every coupling cycle. Following a final deprotection with a solution of $20 \%$ piperidine in DMF and cleavage with a mixture of TFA/water/triisopropylsilane (90:5:5) for $2 \mathrm{~h}$ at room temperature [74], the crude peptides were repeatedly extracted with diethyl ether and purified using reverse phase preparative HPLC on a Vydac $\mathrm{C}_{18}$ column $(4.6 \times 250 \mathrm{~mm}, 300 \AA, 5 \mathrm{~nm})$. The molecular masses of the peptides were confirmed by using a matrix-assisted laser desorption ionization mass spectrometer (data not shown) (MALDI II, Kratos Analytical Ins.).

\subsection{Interaction of Peptides with Gelatin by CD Spectroscopy}

Gelatin solutions were prepared by weighing the required amount of gelatin flakes and soaking in hot water $\left(40^{\circ} \mathrm{C}\right)$ with stirring. The concentrations quoted here are expressed in weight percentage of gelatin.

CD spectra were recorded at $25^{\circ} \mathrm{C}$ on a Jasco 810 spectropolarimeter (Jasco, Tokyo, Japan) equipped with a temperature control unit using a $0.1-\mathrm{cm}$ path-length quartz cell. The gelatin $(0.1 \%)$ was scanned in the presence of $10 \mathrm{mM}$ SP buffer. The CD spectra were measured for the $0.1 \%$ gelatin samples (dissolved in $10 \mathrm{mM}$ SP buffer ( $\mathrm{pH}$ 7.2)) containing peptide. CD data represent the average value of three separate recordings with four scans per sample. A reference spectrum containing $10 \mathrm{mM} \mathrm{SP}$ buffer was also recorded. The CD spectra of the samples were obtained after subtracting the reference spectrum. Changes in the conformation of gelatin upon addition of peptides were recorded.

\subsection{Interaction of Peptides with Surfactants by CD Spectroscopy}

The CD spectra of the peptides $(50 \mu \mathrm{M})$ were obtained in different environments, including $10 \mathrm{mM}$ SP buffer, $30 \mathrm{mM}$ SDS, and $0.1 \%$ Tween 80 . Ten millimoles of SP buffer was used to prepare $30 \mathrm{mM}$ SDS and $0.1 \%$ Tween 80 . At least five scans in the $250-190 \mathrm{~nm}$ wavelength range were conducted, and 
the average blank spectra were subtracted from the average of the sample spectra. All CD spectra are presented as the mean residue ellipticity, $[\theta]_{\mathrm{MRW}}$, in $\mathrm{deg} \mathrm{cm}^{2} / \mathrm{dmol}$. The alpha-helical content was determined from the mean residue ellipticities at $222 \mathrm{~nm}$, as indicated in Equation 1 [75]:

$$
\% \text { Helix }=\left([\theta]_{\text {obs }} \times 100\right) /\left\{[\theta]_{\text {helix }} \times(1-2.57 / l)\right\}
$$

where $[\theta]_{\mathrm{obs}}$ is the mean-residue ellipticity observed experimentally at $222 \mathrm{~nm},[\theta]_{\text {helix }}$ is the ellipticity of a peptide of infinite length with a $100 \%$ helix population, taken as $-39,500 \mathrm{deg} \mathrm{cm}^{2} / \mathrm{dmol}$, and $l$ is the peptide length or, more precisely, the number of peptide bonds.

\subsection{Interaction of Peptides with Cell Wall Components by CD Spectroscopy}

The peptides were scanned in the presence or absence of LPS $(0.1 \%)$ dissolved in $10 \mathrm{mM} \mathrm{SP}$ buffer. The secondary structures were monitored at a peptide concentration of $50 \mu \mathrm{M}$ in $10 \mathrm{mM}$ SP buffer in the presence of laminarin from digitata laminarin (0.1\%; Sigma-Aldrich, St. Louis, MO, USA) and in the presence of mannan from Saccharomyces cerevisiae (0.1\%; Sigma-Aldrich, St. Louis, MO, USA). CD data represent the average value of three separate recordings.

\subsection{Trp Fluorescence Assay}

The fluorescence emission spectra of the Trp residues in the peptides were monitored in the presence of $10 \mathrm{mM}$ SP buffer, $0.1 \%$ gelatin, $30 \mathrm{mM}$ SDS, cell wall components $(0.1 \%$ LPS, $0.1 \%$ laminarin, and $0.1 \%$ mannan), and $0.1 \%$ Tween 80 . The Trp fluorescence measurements were taken using a spectrofluorometer. The final concentration $(2 \mu \mathrm{M})$ of each peptide was added to $200 \mu \mathrm{L}$ of the above solutions, and each peptide: environment mixture was allowed to interact at $25{ }^{\circ} \mathrm{C}$ for $10 \mathrm{~min}$. Fluorescence was measured at an excitation wavelenth of $280 \mathrm{~nm}$ and an emission wavelength from 300 to $400 \mathrm{~nm}$.

\subsection{Antibacterial Activity}

The antibacterial activities of the peptides against drug-resistant $P$. aeruginosa (3547, 3592, 4007, $4891)$ were examined using the microbroth dilution method. Aliquots of bacterial suspensions $(50 \mu \mathrm{L})$ in mid-log phase at a concentration of $2 \times 10^{5}$ colony forming units $(\mathrm{CFUs} / \mathrm{mL})$ in Mueller Hinton Broth (MHB, BD, Sparks, MD, USA) culture medium were added to each well containing $50 \mu \mathrm{L}$ of the peptide solution that had been serially diluted 2-fold in buffer (10 mM SP buffer, $\mathrm{pH} 7.2$ or phosphate buffered saline (PBS); $1.5 \mathrm{mM} \mathrm{KH}_{2} \mathrm{PO}_{4}, 2.7 \mathrm{mM} \mathrm{KCl}, 8.1 \mathrm{mM} \mathrm{Na}_{2} \mathrm{HPO}_{4}, 135 \mathrm{mM} \mathrm{NaCl}, \mathrm{pH}$ 7.2). Several wells were kept untreated as a control in order to monitor bacterial growth. Inhibition of bacterial growth was determined by measuring the absorbance at $620 \mathrm{~nm}$ using a Versa-Max microplate Elisa Reader (Molecular Devices, Sunnyvale, CA, USA) after incubation for $18 \mathrm{~h}$ at $37^{\circ} \mathrm{C}$. The $\mathrm{MIC}$ is defined as the minimal peptide concentration that inhibits bacterial growth. All MIC measurements are the average of three to four independent experiments. The bacterial strains were procured from Chonnam University Hospital, in Gwangju, South Korea. All isolates were stored at $-70{ }^{\circ} \mathrm{C}$ until required. 


\subsection{Cell Culture and Cytotoxicity}

To examine the cytotoxic effects of the peptides, HaCaT (human keratinocyte cell line) cells were cultured in Dulbecco's modified Eagle medium (DMEM) supplemented with antibiotics (100 U/mL of penicillin, $100 \mu \mathrm{g} / \mathrm{mL}$ of streptomycin) and $10 \%$ fetal calf serum at $37{ }^{\circ} \mathrm{C}$ in a humidified chamber containing $5 \% \mathrm{CO}_{2}$. The percentage of growth inhibition was evaluated by MTT (Sigma) assay for the measurement of viable cells. A total of $2 \times 10^{4}$ cells/well was seeded onto a 96-well plate and then incubated for $24 \mathrm{~h}$. Various concentrations of the test peptides were then added to the wells, after which the cells were incubated for an additional $24 \mathrm{~h}$ at $37^{\circ} \mathrm{C}$. Subsequently, $10 \mu \mathrm{L}$ of MTT at a concentration of $5 \mathrm{mg} / \mathrm{mL}$ was added to each of the wells, after which the cells were incubated for an additional $4 \mathrm{~h}$. The supernatants were then aspirated, and $100 \mu \mathrm{L}$ of dimethyl sulfoxide was added to the wells in order to dissolve any remaining precipitate. Absorbance was then measured at a wavelength of $570 \mathrm{~nm}$ using an $\mathrm{EL}_{\mathrm{x}} 800$ reader (Bio-Tek instruments, Inc., Winooski, VT).

\section{Conclusion}

The native structure of gelatin was not altered upon treatment with peptides. Therefore, changes in the structural properties of gelatin upon interaction with peptides assist the preparation of gelatin-peptide sheets. In this study, the tested peptides showed antimicrobial activity, which suggests that they might be useful in the development of a topical application for wound sites. Among them, $(\mathrm{KW})_{4}$ possesses a simple composition with microbial selective properties, making it economically viable for many applications, including inhibition of bacterial infection at wound sites.

\section{Acknowledgements}

This work was supported by a National Research Foundation of Korea (NRF) grant funded by the Korea government (MEST) (No. 2011-0017532) and the Human Resource Training Project for Regional Innovation.

\section{References}

1. Greenfield, N.J. Methods to estimate the conformation of proteins and polypeptides from circular dichroism data. Anal. Biochem. 1996, 235, 1-10.

2. Johnson, W.C. Secondary structure of proteins through circular dichroism spectroscopy. Annu. Rev. Biophys. Biophys. Chem. 1988, 17, 145-166.

3. Johnson, W.C. Analyzing protein circular dichroism spectra for accurate secondary structures. Proteins 1999, 35, 307-312.

4. Yeaman, M.R.; Yount, N.Y. Mechanism of antimicrobial peptide action and resistance. Pharmacol. Rev. 2003, 55, 27-55.

5. Hancock, R.E.; Chapple, D.S. Peptide antibiotics. Antimicrob. Agents Chemother. 1999, 43, 1317-1323.

6. Powers, J.P.; Hancock, R.E. The relationship between peptide structure and antibacterial activity. Peptides 2003, 24, 1681-1691. 
7. Greenfield, N.J. Applications of circular dichroism in protein and peptide analysis. Trend Anal. Chem. 1999, 18, 236-244.

8. Gopal, R.; Kim, Y.J.; Seo, C.H.; Hahm, K.S.; Park, Y. Reversed sequence enhances antimicrobial activity of a synthetic peptide. J. Peptide Sci. 2011, 17, 329-334.

9. Gopal, R.; Park, S.C.; Ha, K.J.; Cho, S.J.; Kim, S.W.; Song, P.I.; Nah, J.W.; Park, Y.; Hahm, K.S. Effect of leucine and lysine substitution on the antimicrobial activity and evaluation of the mechanism of the HPA3NT3 analog peptide. J. Peptide Sci. 2009, 15, 589-594.

10. Patrzykat, A.; Gallant, J.W.; Seo, J.K.; Pytyck, J.; Douglas, S.E. Novel antimicrobial peptides derived from flatfish genes. Antimicrob. Agents Chemother. 2003, 47, 2464-2470.

11. Zasloff, M. Magainins, a class of antimicrobial peptides from Xenopus skin: Isolation, characterization of two active forms, and partial cDNA sequence of a precursor. Proc. Natl. Acad. Sci. USA 1987, 84, 5449-5453.

12. Kawanishi, N.; Christenson, H.K.; Ninham, B.W.J. Measurement of the interaction between adsorbed polyelectrolytes: Gelatin on mica surfaces. J. Phys. Chem. 1990, 94, 4611-4617.

13. Likos, C.N.; Vaynberg, K.A.; Lowen, H.; Wagner, N.J. Colloidal stabilization by adsorbed gelatin. Langmuir 2000, 16, 4100-4108.

14. Tabata, Y.; Ikada, Y. Protein release from gelatin matrices. Adv. Drug Deliv. Rev. 1998, 31, 287-301.

15. Wetzel, R.; Buder, E.; Hermel, H.; Hütter, A. Conformations of different gelatins in solutions and in films an analysis of circular dichroism (CD) measurements. Colloid Polym. Sci. 1987, 265, 1036-1045.

16. Gardi, A.; Nischmann, H.S. Intracatenar cross-linking in gelatin with carbodiimide. Helv. Chim. Acta. 1972, 55, 2468-2486.

17. Wustneck, R.; Buder, E.; Wetzel, R.; Hermel, H. The modification of the triple helical structure of gelatin in aqueous solution 3. The influence of cationic surfactants. Colloid Polym. Sci. 1989, 267, 429-433.

18. Wustneck, R.; Buder, E.; Wetzel, R.; Hermel, H. The modification of the triple helical structure of gelatin in aqueous solution 1. The influence of anionic surfactants, $\mathrm{pH}$-value, and temperature. Colloid Polym. Sci. 1988, 266, 1061-1067.

19. Guillen, M.C.G.; Turnay, J.; Fernandez-Diaz, M.D.; Ulmo, N.; Lizarbe, M.A.; Montero, P. Structural and physical properties of gelatin extracted from different marine species: A comparative study. Food Hydrocoll. 2002, 16, 25-34.

20. Engel, J; Prockop, D.J. The zipper-like folding of collagen triple helices and the effects of mutations that disrupt the zipper. Annu. Rev. Biophys. Biophys. Chem. 1991. 20, 137-152.

21. Gayatri, R.; Sharma, A.K.; Rajaram, R.; Ramasami, T. Chromium (III)-induced structural changes and self-assembly of collagen. Biochem. Biophys. Res. Commun. 2001, 283, 229-235.

22. Leikina, E.; Mertts, M.V.; Kuznetsova, N.; Leikin, S. Type 1 collagen is thermally unstable at body temperature. Proc. Natl. Acad. Sci. USA 2002, 99, 1314-1318.

23. Goo, H.C.; Hwang, Y.S.; Choi, Y.R.; Cho, H.N.; Suh, H. Development of collagenase-resistant collagen and its interaction with adult human dermal fibroblasts. Biomaterials 2003, 24, 5099-5113.

24. Madhan, B.; Subramanian, V.; Rao, J.R.; Nair, B.U.; Ramasami, T. Stabilization of collagen using plant polyphenol: Role of catechin. Int. J. Biol. Macromol. 2005, 37, 47-53. 
25. Fathima, N.N.; Devi, R.S.; Rekha, K.B.; Dhathathreyan, A. Collagen-curcumin interaction-A physico-chemical study. J. Chem. Sci. 2009, 121, 509-514.

26. Rosenblum, G.; Van den Steen, P.E.; Cohen, S.R.; Bitler, A.; Brand, D.D.; Opdenakker, G.; Sagi, I. Direct visualization of protease action on collagen triple helical structure. Plos One 2010, 5, doi:10.1371/journal.pone.0011043.

27. Mitra, T.; Sailakshmi, G.; Gnanamani, A.; Mandal, A.B. Di-carboxylic acid cross-linking interactions improves thermal stability and mechanical strength of reconstituted type I collagen. Part I. Oxalic acid. J. Therm. Anal. Calorim. 2011, 105, 325-330.

28. Ramachandran, G.N.; Kartha, G. Structure of collagen. Nature 1955, 176, 593-595.

29. Rich, A.; Crick, F.H. The structure of collagen. Nature 1955, 176, 915-916.

30. Cowan, P.M.; McGavin, S.; North, A.C. The polypeptide chain configuration of collagen. Nature 1955, 176, 1062-1064.

31. Fathima, N.N.; Madhan, B.; Rao, J.R.; Nair, B.U. Effect of zirconium (IV) complexes on the thermal and enzymatic stability of type I collagen. J. Inorg. Biochem. 2003, 95, 47-54.

32. Fathima, N.N.; Bose, M.C.; Rao, J.R.; Nair, B.U. Stabilization of type I collagen against collagenases (type I) and thermal degradation using iron complex. J. Inorg. Biochem. 2006, 100, 1774-1780.

33. Fathima, N.N.; Suresh, R.; Rao, J.R.; Nair, B.U. Role of green tea polyphenols cross linking in alleviating UV radiation effect on collagen. J. Appl. Polym. Sci. 2007, 104, 3642-3648.

34. Franzblau, C.; Schmid, K.; Faris, B.; Beldekas, J.; Garvin, P.; Kagan, H.M.; Bruce, J.; Baum, B.J. The interaction of collagen with alphal-acid glycoprotein. Biochim. Biophys. Acta 1976, 427, 302-314.

35. Madhan, B.; Muralidharan, C.; Jayakumar, R. Study on the stabilisation of collagen with vegetable tannins in the presence of acrylic polymer. Biomaterials 2002, 23, 2841-2847.

36. Fathima, N.N.; Madhan, B.; Rao, R.T.; Nair, B.U.; Ramasami, T. Interaction of aldehydes with collagen: Effect on thermal enzymatic and conformational stability. Int. J. Biol. Macromol. 2004, 4, 241-247.

37. Usha, R.; Rajaram, A.; Ramasami, T. Stability of collagen in the presence of 3,4-dihydroxyphenylalanine (DOPA). J. Photochem. Photobiol. B 2009, 97, 34-39.

38. Ge, Y.; Macdonald, D.L.; Holroyd, K.J.; Thornsberry, C.; Wexler, H.; Zasloff, M. In vitro antibacterial properties of pexiganan, an analog of magainin. Antimicrob. Agents Chemother. 1999, $43,782-788$.

39. Gopinath, D.; Kumar, M.S.; Selvaraj, D.; Jayakumar, R. Pexiganan-incorported collagen matrices for infected wound-healing processes in rat. J. Biomed. Mater. Res. A 2005, 73, 320-331.

40. Townsend, D.M.; Tew, K.D.; Tapiero, H. The importance of glutathione in human disease. Biomed. Pharmacother. 2003, 57, 145-155.

41. Arul, V.; Gopinath, D.; Gomathi, K.; Jayakumar, R. Biotinylated GHK peptide incorporated collagenous matrix: A novel biomaterial for dermal wound healing in rats. J. Biomed. Mater. Res. B Appl. Biomater. 2005, 73, 383-391.

42. Schibli, D.J.; Epand, R.F.; Vogel, H.J.; Epand, R.M. Tryptophan-rich antimicrobial peptides: Comparative properties and membrane interactions. Biochem. Cell Biol. 2002, 80, 667-677. 
43. Dathe, M.; Wieprecht, T. Structural features of helical antimicrobial peptides: Their potential to modulate activity on model membranes and biological cells. Biochim. Biophys. Acta 1999, 1462, 71-87.

44. Tossi, A.; Sandri, L.; Giangaspero, A. Amphipathic, alpha-helical antimicrobial peptides. Biopolymers 2000, 55, 4-30.

45. Powers, J.P.S.; Hancock, R.E.W. The relationship between peptide structure and antibacterial activity. Peptides 2003, 24, 1681-1691.

46. Huang, Y.; Huang, J.; Chen, Y. Alpha-helical cationic antimicrobial peptides: Relationships of structure and function. Protein Cell 2010, 1, 143-152.

47. Woody, R.W. Contributions of tryptophan side chains to the far-ultraviolet circular dichroism of proteins. Eur. Biophys. J. 1994, 23, 253-262.

48. Ladokhin, A.S.; Selsted, M.E.; White, S.H. Bilayer interactions of indolicidin, a small antimicrobial peptide rich in tryptophan, proline, and basic amino acids. Biophys. J. 1997, 72, 794-805.

49. Liu, Z.; Brady, A.; Young, A.; Rasimick, B.; Chen, K.; Zhou, C.; Kallenbach, N.R. Length effects in antimicrobial peptides of the (RW) $)_{n}$ series. Antimicrob. Agents Chemother. 2007, 51 597-603.

50. Mollmann, S.H.; Elofsson, U.; Bukrinsky, J.T.; Frokjaer, S. Displacement of adsorbed insulin by tween 80 monitored using total internal reflection fluorescence and ellipsometry. Pharm. Res. 2005, 22, 1931-1941.

51. Torrent, M.; Navarro, S.; Moussaoui, M.; Nogues, M.V.; Boix, E. Eosinophil cationic protein high-affinity binding to bacteria-wall lipopolysaccharides and peptidoglycans. Biochemistry 2008, 47, 3544-3555.

52. Ding, L.; Yang, L.; Weiss, T.M.; Waring, A.J.; Lehrer, R.I.; Huang, H.W. Interaction of antimicrobial peptides with lipopolysaccharides. Biochemistry 2003, 42, 12251-12259.

53. Rosenfeld, Y.; Sahl, H.G.; Shai, Y. Parameters involved in antimicrobial and endotoxin detoxification activities of antimicrobial peptides. Biochemistry 2008, 47, 6488-6478.

54. Van der Weerden, N.L.; Hancock, R.E.; Anderson, M.A. Permeabilization of fungal hyphae by the plant defension NAD1 occurs through a cell wall dependent process. J. Biol. Chem. 2010, 285, 37513-37520.

55. Lee, D.G.; Kim, D.H.; Park, Y.; Kim, H.K.; Shin, Y.K.; Choi, C.H.; Hahm, K.S. Fungicidal effect of antimicrobial peptides, PMAP-23, isolated from porcine myeloid against Candida albicans. Biochem. Biophys. Res. Commun. 2001, 282, 570-574.

56. Zhao, H.; Kinnunen, P.K.J. Binding of the antimicrobial peptide temporin L to liposomes assessed by Trp fluorescence. J. Biol. Chem. 2002, 277, 25170-25177.

57. Swamy, R.N.; Gnanamani, A.; Shanmugasamy, S.; Gopal, R.K.; Mandal, A.B. Bioinformatics in crosslinking chemistry of collagen with selective cross linkers. BMC Res. Notes 2011, 4, doi:10.1186/1756-0500-4-399.

58. Chan, D.I.; Prenner, E.J.; Vogel, H.J. Tryptophan- and arginine-rich antimicrobial peptides: Structure and mechanism of action. Biochim. Biophys. Acta 2006, 1758, 1184-1202.

59. Chen, C.C.; Hsu, W.; Hwang, K.C.; Hwu, J.R.; Lin, C.C.; Horng, J.C. Contributions of cation- $\pi$ interactions to the collagen triple helix stability. Arch. Biochem. Biophys. 2011, 508, 46-53. 
60. Edwards, R.; Harding, K.G. Bacteria and wound healing. Curr. Opin. Infect. Dis. 2004, 17, 91-96.

61. Kustos, T.; Kustos, I.; Kilar, F.; Rappai, G.; Kocsis, B. Effect of antibiotics on cell surface hydrophobicity of bacteria using orthopedic wound infections. Chemotherapy 2003, 9, 237-242.

62. Gomathi, K.; Gopinath, D.; Rafiuddin Ahmed, M.; Jayakumar, R. Quercetin incorported collagen matrices for dermal wound healing processes in rat. Biomaterials 2003, 24, 2767-2772.

63. Hima Bindu, T.V.L.; Vidyavathi, M.; Kavitha, K.; Sastry, T.P.; Suresh Kumar, R.V. Preparation and evaluation of chitosan-gelatin composite films for wound healing activity. Trends Biomater. Artif. Organs 2010, 24, 123-130.

64. Hima Bindu, T.V.L.; Vidyavathi, M.; Kavitha, K.; Sastry, T.P. Preparation and evaluation of gentamicin loaded chitosan-gelatin composite films for wound healing activity. Int. J. Appl. Biol. Pharm. Technol. 2011, 2, 453-463.

65. Iwakura, A.; Tabata, Y.; Tamura, N.; Doi, K.; Nishimura, K.; Nakamura, T.; Shimizu, Y.; Fujita, M.; Komeda, M. Gelatin sheet incorporating basic fibroblast growth factor enhances healing of devascularized sternum in diabetic rats. Circulation 2001, 104, I325-I329.

66. Hima Bindu, T.V.L.; Vidyavathi, M.; Kavitha, K.; Sastry, T.P.; Suresh Kumar, R.V. Preparation and evaluation of ciprofloxacin loaded chitosan-gelatin composite films for wound healing activity. Int. J. Drug. Deliv. 2010, 2, 173-182.

67. Thakur, G.; Mitra, A.; Rousseau, D.; Basak, A.; Sarkar, S.; Pal, K. Crosslinking of gelatin-based drug carriers by genipin induces changes in drug kinetic profiles in vitro. J. Mater. Sci. Mater. Med. 2011, 22, 115-123.

68. Gomez-Guillen, M.C.; Perez-Mateos, M.; Gomez-Estaca, J.; Lopez-Caballero, E.; Gimenez, B.; Montero, P. Fish gelatin: A renewable material for developing active biodegradable film. Trends Food Sci. Technol. 2009, 20, 3-16.

69. Akane, T.; Toshiaki, N.; Hiroshi, M. Acceleration of wound healing by gelatin film dressings with epidermal growth factor. J. Vet. Med. Sci. 2005, 67, 909-913.

70. Baker, M.A.; Maloy, W.L.; Zasloff, M.; Jacob, L.S. Anticancer efficacy of magainin 2 and analogue peptides. Cancer Res. 1993, 53, 3052-3057.

71. Johnstone, S.A.; Gelmon, K.; Mayer, L.D.; Hancock, R.E.W.; Bally, M.B. In vitro characterization of the anticancer activity of membrane-active cationic peptides. I. Peptide-mediated cytotoxicity and peptide-enhanced cytotoxic activity of doxorubicin against wild-type and $p$-glycoprotein over-expressing tumor cell lines. Anticancer Drug Des. 2000, 15, 151-160.

72. Gallo, R.L.; Ono, M.; Povsic, T.; Page, C.; Eriksson, E.; Klagsbrun, M.; Bernfield, M. Syndecans, cell surface heparan sulfate proteoglycans, are induced by a proline-rich antimicrobial peptide from wounds. Proc. Natl. Acad. Sci. USA 1994, 91, 11035-11039.

73. Hancock, R.E.; Sahl, H.G. Antimicrobial and host defense peptides as new anti-infective therapeutic strategies. Nat. Biotechnol. 2006, 24, 1551-1557.

74. Atherton, E.; Sheppard, R.C. Solid Phase Peptide Synthesis: A Practical Approach; IRL Press: Oxford, UK, 1989. 
75. Chen, Y.H.; Yang, J.T.; Chau, K.H. Determination of the helix and beta from of proteins in aqueous solution by circular dichroism. Biochemistry 1974, 13, 3350-3359.

(C) 2012 by the authors; licensee MDPI, Basel, Switzerland. This article is an open access article distributed under the terms and conditions of the Creative Commons Attribution license (http://creativecommons.org/licenses/by/3.0/). 